\title{
Long-term outcomes associated to video-assisted thoracic sympathotomy for palmar-axillar subtype of the hyperhidrosis
}

\author{
Resultados tardios da simpatotomia torácica vídeo-assistida para tratamento do subtipo \\ palmar-axilar de hiperidrose
}

Leandro Pretto Flores

\begin{abstract}
Objective: Surgery for both palmar and axillar hyperhidrosis usually includes the interruption of the sympathetic chain in multiple levels. This study aimed to determine the long-term outcomes associated to video-assisted thoracic sympathotomy (VATS) of T2, T3 and T4 ganglia for these cases. Methods: Analysis of the outcomes obtained from 36 patients regarding the rate of resolution of the symptoms and the compensatory sweating (CS). All subjects were followed-up for 36 months. Results: Good outcomes were observed in $98.6 \%$ for palmar and $60 \%$ for axillary hyperhidrosis ( $p=0.0423$ ), respectively. Of the subjects, $86 \%$ reported some postoperative episode of CS, however only $45 \%$ $(p=0.0031)$ still noticed it at the end of the follow-up period. Conclusions: VATS is effective for the excessive palmar sweating, whereas it is fully efficient for only two thirds of the cases sustaining associated axillar hyperhidrosis. CS is expected as a rule following the proposed operative protocol, however it is usually self-limited.
\end{abstract}

Key words: hyperhidrosis, video-assisted thoracic sympathectomy, ganglia, sympathetic, neuroendoscopy.

RESUMO

Objetivo: A cirurgia para hiperidrose palmar e axilar usualmente inclui a interrupção da cadeia simpático-torácica em múltiplos níveis. Este estudo objetivou apresentar os resultados tardios associados à simpatectomia torácica vídeo-assistida (STVA) dos gânglios T2,T3 e T4 nesses casos. Métodos: Foram analisados os resultados cirúrgicos obtidos em 36 pacientes quanto à taxa de resolução dos sintomas e à ocorrência de hiperidrose compensatória (HC). Todos os sujeitos foram acompanhados por 36 meses. Resultados: Bons resultados foram observados em $98,6 \%$ dos pacientes para a forma palmar e em $60 \%$ para a forma axilar ( $p=0,0423$ ). Em $86 \%$ dos casos, havia relato de algum episódio de HC, mas apenas 45\% ainda notavam sua ocorrência ao final do período de acompanhamento. Conclusões: A STVA é eficaz para o tratamento da hiperidrose palmar, mas mostrou-se plenamente satisfatória em apenas dois terços dos casos associados à forma axilar. A HC deve ser considerada ocorrência esperada no protocolo cirúrgico; no entanto, evolui de maneira autolimitada na maioria dos casos.

Palavras-Chave: hiperidrose, simpatectomia torácica vídeo-assistida, gânglios simpáticos, neuroendoscopia.

Although endoscopic thoracic sympathectomy was introduced by Kux in $1950^{1}$, due to technical difficulties and high recurrence rates, it did not become popular until the adoption of video technology in the early $1990^{2,3}$, thereby receiving the name of video-assisted thoracoscopic sympathectomy (VATS). Subsequently, these endoscopic techniques have been refined, reducing the invasiveness with shorter incisions and less input portals ${ }^{4,5}$. Its popularity has been such that the technique has spread throughout the world and, currently, there are groups - mainly Swedes and Japaneses with large experience ${ }^{6}$.
Hyperhidrosis $(\mathrm{HH})$ is defined as an excessive eccrine sweat production in one or more levels of the organism. Often results in serious disruption of the patient's social and occupational behavior. It is accepted that normal skin sweating could range between 8 and $15 \mathrm{mcg} / \mathrm{cm}^{2} / \mathrm{min}$, including the surface of both hands. $\mathrm{HH}$ is a condition of unknown origin that begins in childhood, occurs in adolescence and - without specific treatment - persists throughout life ${ }^{7}$. It is characterized as an increase of sweating beyond what is required for the control of thermoregulation in one or more body areas, especially at the hands; however, it is also frequent at the axilla,

M.D; Section of Neurological Surgery, Santa Helena Hospital. Unit of Neurosurgery, Hospital de Base do Distrito Federal. Post-Graduate Program in Medical Science, University of Brasília (UnB), Brasília DF, Brazil.

Correspondence: Leandro Pretto Flores; SQN 208 / Bloco F / apto.604; Asa Norte; 70853-060 Brasília DF - Brasil; E-mail: leandroprettoflores@hotmail.com Conflict of interest: There is no conflict of interest to declare.

Received 12 January 2012; Received in final form 26 January 2012; Accepted 03 February 2012 
feet and face. The disease has a slight female predominance and in $25-65 \%$ of cases there are other affected relatives (familial variant); some authors suggested an inheritance with variable penetrance ${ }^{8}$.

VATS is highly effective for treatment of $\mathrm{HH}$, by interrupting the sympathetic tone and impulses from the sympathetic ganglia to the eccrine glands, and it is considered as the firstline treatment for the palmar subtype ${ }^{9}$. However, the surgery changes the cutaneous innervation of the sweating glands and may provoke different degrees of compensatory sudoresis.

Moreover, most of the current evidence regarding VATS surgery comes from observational studies. There is a lack of uniformity about the description of the measures and methods used to demonstrate the results, making difficult to compare different series and draw general conclusions ${ }^{10}$.

A number of studies have already compared the effectiveness of sectioning the sympathetic chain in different levels for treatment of different clinical subtypes of the disease (i.e., palmar, axillar, plantar and craniofacial $)^{11-14}$. Our clinical experience has demonstrated that a great number of patients complaints of both palmar and axillar $\mathrm{HH}$, and surgery for these cases, must include the interruption of the sympathetic pathway in multiple levels. Hence, this study aimed to define the long-term surgical results associated to transection of the upper sympathetic chain (T2, T3 and T4 ganglia) for treatment of both palmar and axillar $\mathrm{HH}$, with special attention regarding the resolution of the symptoms and the associated compensatory sweating.

\section{METHODS}

From 2002 to 2009, author performed 64 VATS for treatment of patients sustaining $\mathrm{HH}$ or complex regional pain of the upper limb. For this study, we included only those subjects who underwent surgery for treatment of both palmar and axillar hyperhidrosis, and whose minimal follow-up time frame was 36 months. Patients in whom surgery was motivated by palmar or axillar solely $\mathrm{HH}$, or those in whom the procedure was indicated for treatment of complex regional pain, were excluded from the analysis. Moreover, we do not consider patients with prior thoracic surgery, cardiac diseases, pulmonary infections, neoplasia or pleural and/or lung diseases, that could increase the surgical risk as candidates to this surgery. Written informed consent was obtained from each participant, and the study was carried out in accordance with the Declaration of Helsinki II.

Thirty-six months after surgery, all patients answered a quality-of-live questionnaire, based in a model previously described by de Lima et al. ${ }^{15}$. The following results of the questionnaire were evaluated in this study: a) objective quantification of sweating in hands (right and left) and in axillas (right and left). For this purpose, we considered as good outcomes the reported reduction of the sweating from 80 to $100 \%$, as fair results the reduction from 50 to $79 \%$, and as poor outcomes those cases reporting reduction lower than 49\%; b) the presence or absence of compensatory hyperhidrosis $(\mathrm{CH})$, by evaluating its intensity and location. The intensity of $\mathrm{CH}$ was graded as mild, moderate or severe according to the patient's perception. It was considered severe when the sweat was visible, thereby causing embarrassment and leading to the need to change clothes every day.

Data processing was performed using commercially available statistical software (SPSS, version 16.0 for Windows, SPSS, Inc. Chicago, IL). Comparisons were carried out using the Mann-Whitney U test, and a probability value less than 0.05 were considered significant.

\section{Surgical technique}

All patients were operated on by the same surgeon, using the same technique, i.e., a bilateral T2, T3 and T4 simpathotomy. Patients underwent surgery under general anesthesia, in a lateral decubitus position; the lungs were deflated by using a single lumen endotracheal tube and applying low volume and high frequency pulmonary ventilation. Two mini-incisions of approximately $5.5 \mathrm{~mm}$ each were made: the first into the fifth intercostal space on the anterior axillary line (in the submammary sulcus for the women), through which a $5 \mathrm{~mm}$ diameter video-camera was introduced (Carl Storz, Culver City, California); and the second into the third intercostal space on the mid-axillary line, through which an harmonic scalpel was introduced. Under direct endoscopic observation, the sympathetic chain was identified: the second rib was localized at the point of its articulation with the spine, as well as the third, fourth and fifth ribs. The sympathetic chain was transected in situ over these rib heads, creating a gap of $5 \mathrm{~mm}$ or more between the stumps of the chain, aiming to isolate T2, T3 and T4 ganglia (Fig 1). The surrounding soft tissues were inspected, in order to confirm the transection and to search for accessory sympathetic nerves. A temporary pleural drainage was applied until lung re-expansion was confirmed by direct endoscopic view, and the wounds were closed with subcuticular sutures. The procedure was repeated on the contralateral side. In cases in which a continuous flow of air was observed during the temporary chest drainage, a 20-French chest tube was then inserted through one of the portals and removed during the following days (usually after 48 hours). Postoperatively, all patients used an incentive spirometer for one week and narcotic analgesics medication as needed. They were usually discharged home at the third postoperative day.

\section{RESULTS}

This study encompassed 36 cases that underwent upper thoracic sympathotomy for treatment of both axillar and palmar HH. There were 21 female and 15 male, and the mean age was 25.3 years (ranging from 16 to 47 years-old). No subject 
was lost follow-up. The duration of the HH was lifelong in 13 cases (36\%); the onset was reported as during childhood in 18 patients (50\%) and during puberty in five subjects (13.8\%). All patients classified their preoperative symptoms as severe and interfering significantly with their activities of daily living. Most of them (23 cases - 63.8\%) had tried other nonsurgical therapies, as local dermatological therapies (creams and lotions), local application of botulinun toxin type A or medications such as propanolol or oxybutynin.

The palmar HH was completely alleviated (anhidrosis $100 \%$ of sweating resolution) in $91 \%$ of the cases (33 subjects) on the right hand; two cases (5\%) reported reduction of $90 \%$ of the sweating; and one case (2\%) noted relief of $80 \%$ of the preoperative symptoms. On the left hand, the results were the following: $100 \%$ of resolution in 32 cases (88\%), $90 \%$ in one case (2\%), two cases (5\%) as $80 \%$, and $70 \%$ of sweating reduction in one case (2\%). Conversely, the axillary $\mathrm{HH}$ was completely resolved in only 17 cases on the right side (48\%) and in 16 subjects in the left side (45\%). On the right axilla, five patients (16\%) reported significant improvement, but experienced some residual sweating (70\% of symptoms resolution), and the same was observed in five cases on the left axilla. Fair outcomes $(50 \%$ of sweating reduction) were associated to $36 \%$ of the cases on the right axilla (13 cases) and $41 \%$ on the left side (14 subjects), and poor outcomes (no improvement in symptoms) were observed in one case bilaterally (2\%). Fig 2 demonstrates a comparison between the outcomes associated to each site. Table 1 demonstrates that the simpathotomy of T2, T3 and T4 is more efficient for treatment of the palmar hyperhidrosis than axillar sudoresis, as statistically significant difference between these sites were observed (Mann-Whitney U test, $\mathrm{p}=0.0423$ for good outcomes and $\mathrm{p}=0.0014$ for fair outcomes).

Thirty-one patients $(86 \%)$ reported some episode of $\mathrm{CH}$ following surgery, however, at the moment in which the questionnaire was answered, only $45 \%$ of them (16 subjects) still noticed some degree of body sweating (difference statistically significant, Mann-Whitney U test, p=0.0031) (Table 2).
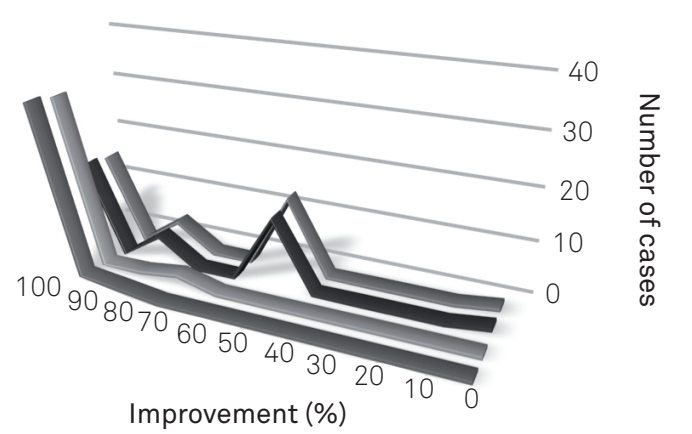

- Palmar Right - Palmar Left - Axila Right - Axila Left

VATS: video-assisted thoracic sympathotomy.

Fig 2. Chart comparing the outcomes observed 36 months following VATS regarding palmar and axillar hyperhidrosis on the left and the right side.

Table 1. Comparison between the outcomes regarding improvement of palmar and axilar sweating 36 months following VATS. The number of cases demonstrated for each outcome's cohort represents the mean of cases observed for the left and right side.

\begin{tabular}{lccc} 
Outcome & Palmar & Axilar & p-value \\
Good (80-100\%) & 35.5 & 21.5 & $0.0423^{\star}$ \\
Fair (50-79\%) & 0.5 & 13.5 & $0.0014^{\star}$ \\
Poor (0-49\%) & 00 & 01 & - \\
\hline *Statically significant & (p<0.05). & VATS: & video-assisted thoracic \\
sympathotomy. & & &
\end{tabular}

Table 2. Incidence of compensatory hyperhidrosis in patients who underwent video-assisted bilateral thoracic sympathotomy, 36 months following surgery.

\begin{tabular}{lccc} 
& Past $^{*}$ & Currently & p-value \\
With $\mathrm{CH}$ & $31(86 \%)$ & $16(45 \%)$ & $0.0031^{* *}$ \\
Without $\mathrm{CH}$ & $05(14 \%)$ & $20(55 \%)$ & $0.0026^{* *}$ \\
p-value & $0.0013^{* *}$ & 0.0791 & \\
\hline
\end{tabular}

*Past: Interval of time between the immediate postoperative period and one week before answering the questionnaire. ${ }^{*}$ Statistically significant $(p<0.05)$. $\mathrm{CH}$ : compensatory hiperhidrosis.
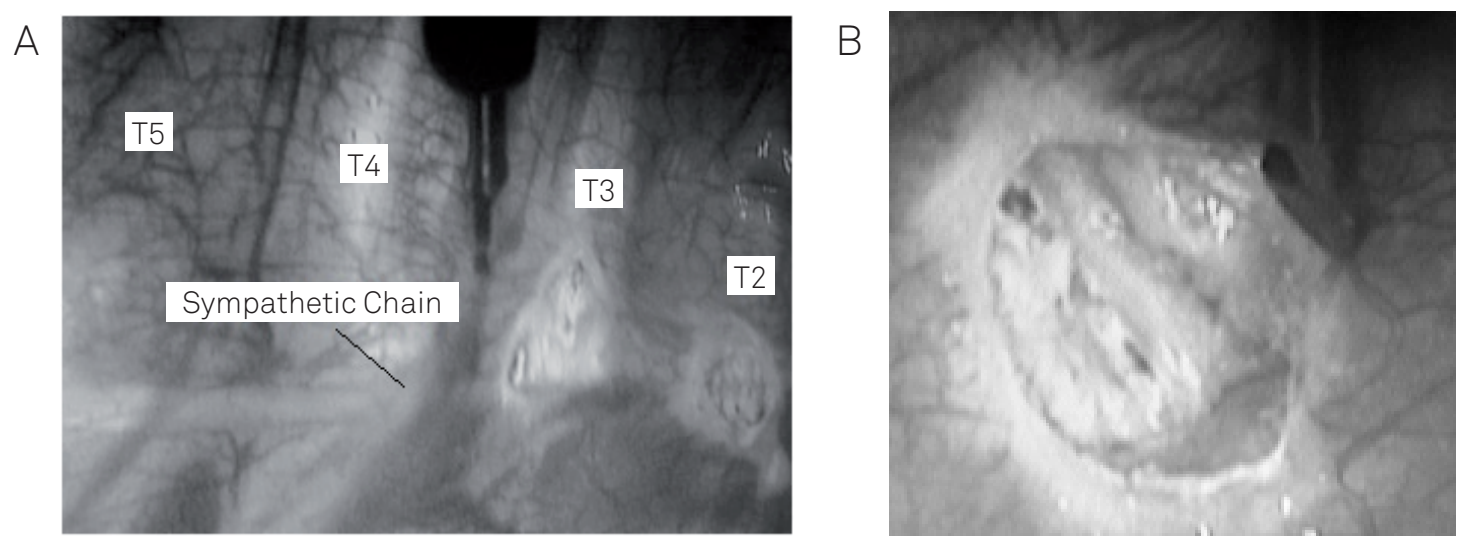

Fig 1. Photograph of the surgical technique. (A) Operative approach to the right side (cranial is to the right side): observe that the lesions were performed over the second and the third rib head. The sympathetic chain is still intact over the fourth and the fifth rib. (B) Close up of the lesion, demonstrating the $5 \mathrm{~mm}$ gap created in the sympathetic chain. 
Eleven subjects (68.7\%) considered their current $\mathrm{CH}$ as mild, exhibiting symptoms only with exercise or exposure to warm environment in rest. Four patients (25\%) described as moderate symptoms, considered as bothersome, but not disabling. Overall, only one subject (6.2\%) considered the $\mathrm{CH}$ as severe. For those 31 cases that experienced some episode of $\mathrm{CH}$, it was noted on the dorsum by 7 patients (19.4\%), on the abdomen in 20 (55.5\%), on the thigh in $6(16.6 \%)$ and in other sites (such as plantar, face or chest) in 3 cases (8.3\%).

There were few complications associated to the surgical technique, such as: maintenance of closed pleural drainage for 48 hours due to residual pneumothorax in 14 cases (38.8\%); two patients experienced transient intercostal neuralgia (5.5\%), which was completely resolved in two months; and in one patient $(2.7 \%)$ the section of the sympathetic chain at the level of the fourth and fifth ribs was aborted due to the presence of intense pleural adhesions on both sides. Horner's syndrome, wound infection or tension pneumothorax was not observed in any case.

\section{DISCUSSION}

The pathophysiology of focal HH is poorly understood. There are about four million of sweat glands in the body, of which about three million are eccrine and apocrine. The eccrine glands are innervated by postganglionic cholinergic fibers of the sympathetic nervous system, and its primary function is to secret the sweat at a rate less than $1 \mathrm{~mL} / \mathrm{m}^{2} / \mathrm{min}$ at rest and at room temperature. These eccrine glands are distributed over almost the entire body surface, although their density is higher in the soles and the forehead, followed by clapping of hands and cheeks. Clinical studies have not found histopathological changes in the sweating glands or increases in the size or number of them ${ }^{16}$. Rather, the focal $\mathrm{HH}$ represent a complex dysfunction of autonomic nervous system: the increased sympathetic activity through T2-T3 ganglia may cause excessive palmar perspiration, causing a vicious circle, since the cooling of the skin by evaporation triggers a sympathetic hyperactivity, which, in turn, increases the sweating ${ }^{17}$.

In mild or moderate cases, non-surgical therapies as topical agents (aluminum hydrochloride hexahydrate at 20-25\% alcohol solution, glutaraldehyde solution 2-10\%), iontophoresis (3-6 sessions per week), oral drugs (oxybutynin, glycopyrrolate) and botulinum toxin type A may be useful $^{18}$. VATS should be indicated for cases considered as severe, which usually involves psychological, professional and social suffering. Different options for chain interruption have been proposed, and none has proven superior to the others ${ }^{19,20}$. The simple section of the sympathetic chain, resection of ganglia, resection of the entire chain, ablation and thermocoagulation are considered as definitive techniques. Interruption of the chain using staples ("clipping ") is described as being potentially reversible ${ }^{21}$. Simple transection of the nervous pathway (denominated as simpathotomy) has been our technique of choice due to the ease for its application: surgery become faster and safer, reducing the blood loss, the lung manipulation, the time of lung deflating and the risk of damaging some of the vital intrathoracic structures (as the azygos vein).

Although almost every patient submitted to VATS demonstrates anhydrosis at the affected area immediately following surgery, the long-term effects of the procedure are still fairly studied. Outcomes may vary according to the different denervated areas, and sometimes it is difficult to provide patients and their families with expectations about the definitive results of the operative procedure ${ }^{22}$. By reviewing our patients three years after surgery, we had the opportunity to analyze what we could consider as the definitive outcome of our technique, determining the real potential of the proposed surgical approach.

Most of the studies suggest that lesions inflicted at different levels of sympathetic chain are indicated for the treatment of the different clinical subtypes of the disease. For example, most authors agree that $\mathrm{T} 2$ and $\mathrm{T} 3$ sympathetic ganglia are suitable targets for treatment of palmar hyperhidrosis ${ }^{23}$, and that the T4 ganglia should be injured in order to obtain adequate axillar sympathetic denervation ${ }^{24}$. Recent studies, comparing the therapeutic efficacy regarding multiple and single ganglia sectioning for palmar $\mathrm{HH}$, concluded that the rate of perspiration's relief was $100 \%$ and $95.6 \%$, respectively. In other words, either multiple or single ganglia transection can offer good therapeutic efficacy ${ }^{25}$. In our series of patients sustaining both axillar and palmar $\mathrm{HH}$, the outcomes associated to palmar denervation were significantly better than those associated to axillar denervation. These means that the long-term results of the sympathotomy for palmar symptoms are very satisfactory, as in our hands excellent results are expected in $98.6 \%$ of the cases; whereas the improvement of the axillar sudoresis is much less satisfactory, as good outcomes are expected in only $60 \%$ of the patients. Some of the reasons for such results include: a) the involvement of other sympathetic ganglia supporting the cholinergic tonus to the axillar region; b) the existence of accessory routes innervating the axilla, as those described by Kim et $\mathrm{al}^{26}$, who identified accessory paths medially and laterally to the chain in 9 to $12 \%$ of the cases; c) possible technical concerns of this study, as the use of simple transection instead of resection of the chain ${ }^{27}$.

Compensatory sweating remains as the most challenging side effect of this procedure and it is considered the greatest cause of postoperative dissatisfaction ${ }^{28}$. $\mathrm{CH}$ usually comes with heat or exercise on the chest, abdomen and thighs. It is generally well tolerated and decreases in the following months; it is probably caused by the interruption of the reflex arch between the sympathetic trunk and the hypothalamus $^{29}$. $\mathrm{CH}$ is described to be associated to sympathectomy for palmar hyperhidrosis in 12 to $100 \%$ of the cases. It seems 
to exist a correlation between the severity of the $\mathrm{CH}$ and the extension of the resection, and also between the severity and the ganglion level sectioned in surgery ${ }^{30}$. However, consensus on which levels would be the most appropriate for the treatment is still lacking. Several attempts have been made to determine the optimal strategy to reduce the incidence of $\mathrm{CH}$ while maintaining the high rate of remission of the $\mathrm{HH}$. We observed that $86 \%$ of our cases experienced some degree of sweating in an area different from the one that was targeted with the VATS, and this high incidence can be explained by the following: a) all of our patients underwent section of the sympathetic chain to the level of the fifth rib, expanding the denervated autonomic area; b) Brazil is located in a tropical area, and warm weather is expected during almost the whole year; c) we used a more conservative definition for classifying compensatory sweating as compared to other authors, once for this study the simple presence of sudoresis in areas of the body where it did not exist prior to surgery - except those associated to intense heat or physical exercise - were considered as $\mathrm{CH}$. However, three years following surgery, only $45 \%$ of our patients still noticed some area of compensatory perspiration, and $93 \%$ of these subjects considered it as not disabling. This information is useful for both patients and surgeons: facing a case sustaining a palmar-axillar subtype of $\mathrm{HH}$, the surgeon can extend the chain transection to the level of T4 ganglia, aiming to cure both symptoms. In this situation, the surgeon must inform the patient that the possibility of postoperative $\mathrm{CH}$ is high, however he may also inform that most of the patients usually do not consider such complication as a problem for their quality of life. In fact, most of subjects consider the resolution of the symptoms of the hand and/or axilla much more important for them than the novel developed areas of sweating.

Based in this cohort of patients submitted to VATS for treatment of palmar and axillar HH by simple sectioning the sympathetic chain at the level of the second, third, fourth and fifth rib heads, we can conclude that the procedure is safe and very effective for the excessive palmar component of the sudoresis, whereas it is fully efficient for only two thirds of the axillar component. Nevertheless, even those patients who did not obtain total resolution of the axillar sweating can expect at least a fifty percent of improvement of their symptoms following surgery. On the other hand, compensatory sweating is expected to be a rule following this surgical protocol, but it is usually self-limited and most of the patients do not consider it as a problem for their daily-living activities.

\section{References}

1. Kux E. 1239 cases of thorascopic sympathectomy and vagotomy; preliminary report. Dtsch Med Wochenschr 1953;78:1590-1592.

2. Ahn SS, Machleder HI, Concepcion B, Moore WS. Thoracoscopic cervicodorsal sympathectomy: preliminary results. J Vasc Surg 1994;20:511-517.

3. Banerjee AK, Edmonson R, Rennie JA. Endoscopic transthoracic electrocautery of the sympathetic chain for palmar and axillary hyperhidrosis. Br J Surg 1990;77:1435.

4. Dumont P, Hamm A, Skrobala D, Robin P, Toumieux B. Bilateral thoracoscopy for sympathectomy in the treatment of hyperhidrosis. Eur J Cardiothorac Surg 1997;11:774-775.

5. Kuntz A. The anatomical basis of reflex vasomotor activity and pain of vascular origin. South Med J 1955;48:338-344.

6. Chou SH, Kao EL, Lin CC, Chang YT, Huang MF. The importance of classifi- cation in sympathetic surgery and a proposed mechanism for compensatory hyperhidrosis: experience with 464 cases. Surg Endosc 2006;20:1749-1753.

7. Hornberger J, Grimes K, Naumann M, et al. Multi-Specialty Working Group on the recognition. Diagnosis and Treatment of primary focal hyperhidrosis. J Am Acad Dermatol 2004;51:274-286.

8. Ro KM, Cantor RM, Lange KL, Ahn SS. Palmar hyperhidrosis: evidence of genetic transmission. J Vasc Surg 2002;35:382-386.

9. Baumgartner FJ, Bertin S, Konecny J. Superiority of thoracoscopic sympathectomy over medical management for the palmoplantar subset of severe hyperhidrosis. Ann Vasc Surg 2009;23:1-7.

10. Schünemann HJ, Jaeschke R, Cook DJ, et al. An official ATS statement: grading the quality of evidence and strength of recommendations in ATS guidelines and recommendations. Am J Respir Crit Care Med 2006;174:605-614.

11. Ishy A, de Campos JR, Wolosker N, tal. Objective evaluation of patients with palmar hyperhidrosis submitted to two levels of sympathectomy: T3 and T4. Interact Cardiovasc Thorac Surg 2011;12:545-548.
12. Wolosker N, Yazbek G, Ishy A, de Campos JR, Kauffman P, PuechLeão P. Is sympathectomy at T4 level better than at T3 level for treating palmar hyperhidrosis? J Laparoendosc Adv Surg Tech A 2008;18:102-106.

13. Yazbek G, Wolosker N, de Campos JR, Kauffman P, Ishy A, Puech-Leão P. Palmar hyperhidrosis--which is the best level of denervation using video-assisted thoracoscopic sympathectomy: T2 or T3 ganglion? J Vasc Surg 2005;42:281-285.

14. Dumont P, Denoyer A, Robin P. Long-term results of thoracoscopic sympathectomy for hyperhidrosis. Ann Thorac Surg 2004;78:1801-1807.

15. de Lima AG, Das-Neves-Pereira JC, de Campos JR, Jatene FB. Factors affecting long-term satisfaction after thoracic sympathectomy for palmar and plantar hyperhidrosis. Is the sudomotor reflex the only villain? Interact Cardiovasc Thorac Surg 2011;12:554-557.

16. Sato K, Kang WH, Saga K, Sato KT. Biology of sweat glands and their disorders. II. Disorders of sweat gland function. J Am Acad Dermatol 1989;20:713-726.

17. Shih CJ, Wu J, Lin MT. Autonomic dysfunction in palmar hyperhidrosis. J Auton Nerv Syst 1983;8:33-43.

18. Connolly M, de Berker D. Management of primary hyperhidrosis: a summary of the different treatment modalities. Am J Clin Dermatol 2003;4:681-697.

19. Gossot D, Galetta D, Pascal A, et al. Long-term results of endoscopic thoracic sympathectomy for upper limb hyperhidrosis. Ann Thorac Surg 2003;75:1075-1079.

20. Han PP, Gottfried ON, Kenny KJ, Dickman CA. Biportal thoracoscopic sympathectomy: surgical techniques and clinical results for the treatment of hyperhidrosis. Neurosurgery 2002;50:306-311.

21. Jo KH, Moon SW, Kim YD, et al. New protocol for a reversal operation in endoscopic thoracic sympathetic clamping: pulling back the suture sling linked to the clip under local anesthesia. Surg Laparosc Endosc Percutan Tech 2007;17:29-32. 
22. Lyra RM, Campos JR, Kang DW, et al. Guidelines for the prevention, diagnosis and treatment of compensatory hyperhidrosis. J Bras Pneumol 2008;24:967-977.

23. Liu Y, Yang J, Liu J, et al. Surgical treatment of primary palmar hyperhidrosis: a prospective randomized study comparing T3 and T4 sympathicotomy. Eur J Cardiothorac Surg 2009;35:398-402.

24. Han PP, Kenny K, Dickman CA. Thoracoscopic approaches to the thoracic spine: experience with 241 surgical procedures. Neurosurgery 2002;51:S88-S95.

25. Deng B, Tan QY, Jiang YG, et al. Optimization of sympathectomy to treat palmar hyperhidrosis: the systematic review and metaanalysis of studies published during the past decade. Surg Endosc 2011;25:1893-1901.

26. Kim do H, Hong YJ, Hwang JJ, Kim KD, Lee DY. Topographical considerations under video-scope guidance in the T3,4 levels sympathetic surgery. Eur J Cardiothorac Surg 2008; 33:786-789.

27. Inan K, Goksel OS, Uçak A, et al. Thoracic endoscopic surgery for hyperhidrosis: comparison of different techniques. Thorac Cardiovasc Surg 2008;56:210-213.

28. Wait SD, Killory BD, Lekovic GP, Ponce FA, Kenny KJ, Dickman CA. Thoracoscopic sympathectomy for hyperhidrosis: analysis of 642 procedures with special attention to Horner's syndrome and compensatory hyperhidrosis. Neurosurgery 2010;67:652-656.

29. LinTS,KuoSJ,Chou MC.Uniportalendoscopicthoracic sympathectomy for treatment of palmar and axillary hyperhidrosis: analysis of 2000 cases. Neurosurgery 2002;51:S84-S87.

30. Licht PB, Pilegaard HK. Severity of compensatory sweating after thoracoscopic sympathectomy. Ann Thorac Surg 2004;78:427-431. 